\title{
Predicting Carbonation Depth of Prestressed Concrete under Different Stress States Using Artificial Neural Network
}

\author{
Chunhua Lu and Ronggui Liu \\ Department of Civil Engineering, Jiangsu University, Zhenjiang 212013, China \\ Correspondence should be addressed to Chunhua Lu, luch79@163.com
}

Received 17 February 2009; Revised 7 October 2009; Accepted 25 November 2009

Recommended by Alfredo Weitzenfeld

\begin{abstract}
Two artificial neural networks (ANN), back-propagation neural network (BPNN) and the radial basis function neural network (RBFNN), are proposed to predict the carbonation depth of prestressed concrete. In order to generate the training and testing data for the ANNs, an accelerated carbonation experiment was carried out, and the influence of stress level of concrete on carbonation process was taken into account especially. Then, based on the experimental results, the BPNN and RBFNN models which all take the stress level of concrete, water-cement ratio, cement-fine aggregate, cement-coarse aggregate ratio and testing age as input parameters were built and all the training and testing work was performed in MATLAB. It can be found that the two ANN models seem to have a high prediction and generalization capability in evaluation of carbonation depth, and the largest absolute percentage errors of BPNN and RBFNN are $10.88 \%$ and $8.46 \%$, respectively. The RBFNN model shows a better prediction precision in comparison to BPNN model.
\end{abstract}

Copyright $\odot 2009$ C. Lu and R. Liu. This is an open access article distributed under the Creative Commons Attribution License, which permits unrestricted use, distribution, and reproduction in any medium, provided the original work is properly cited.

\section{Introduction}

In general, properly designed and constructed prestressed, posttensioned concrete (PC) structures have been considered highly durable because of their excellent performance. Recently, however, these concrete structures have been thought to be threatened by certain premature performance impairments worldwide, predominately when defects were present. These problems may continue to manifest themselves [1]. Initiating mechanisms and particular forms of corrosion affecting PC structures include concrete carbonation effects, chlorides and corrosion, influence of concrete cracking, stress corrosion cracking and steel embrittlement, and fatigue [2]. Obviously, the concrete carbonation may be the common degradation mechanism affecting prestressed concrete structures.

The carbonation of concrete is a natural phenomenon that is commonly defined as the chemical reaction between carbon dioxide $\left(\mathrm{CO}_{2}\right)$ and the cement hydration products such as $\mathrm{Ca}(\mathrm{OH})_{2}$ and calcium-silicate-hydrate (C-S-H) [3]. The process of carbonation affects all concretes and cementitious materials exposed to carbon dioxide in the atmosphere or to carbon dioxide dissolved in solutions in contact with steel. The process of concrete carbonation commences at exposed surfaces immediately upon exposure to $\mathrm{CO}_{2}$ and carbonation rates increase for poor quality, porous concretes, and grouts. As a result of carbonation, calcium carbonate $\left(\mathrm{CaCO}_{3}\right)$ is formed and the pore solution $\mathrm{pH}$ (around 13) drops down to 9. When the depth of concrete's carbonation reaches the reinforcement, passivity is lost and metal's corrosion can proceed unimpeded in the presence of moisture and oxygen [4]. Usually, the carbonation depths correspond to a $\mathrm{pH}$ value roughly equal to 9 and are applied either on cores of real structures or on specimens carbonated in laboratory conditions. This colorimetric test is commonly linked with concrete carbonation models, which are based on the diffusion process with the concentration gradient of the exposed $\mathrm{CO}_{2}$ as the driving force in the porous material and usually expressed by a square-root $(\sqrt{t})$ law [5-7]. However, actual buildings consist of composite materials combined with exterior finishing materials, and it is difficult to apply this square-root law to two- or threedimensional objects. Hence, more sophisticated models, which take account of not only the diffusion process but also the noninstantaneous chemical reactions $[8,9]$, have been developed. 
Even so, it is still difficult to build a calculated model of carbonation depth that can describe all conditions of concrete carbonation, on account of the complexity of carbonation process. On the other hand, when the prior knowledge of the behavior of concrete carbonation is not available, the conventional model cannot be employed either. In such situations, artificial neural network (ANN) is a viable solution and can effectively be used to assess the carbonation depths. ANN is an information processing paradigm that is inspired by the way biological nervous systems, such as the brain, process information. It is composed of a large number of highly interconnected processing elements (neurons) working in unison to solve specific problems. A trained neural network can be thought of as an "expert" in the category of information it has been given to analyze. This expert can then be used to provide projections for given new situations of interest [10].

Recently, ANNs have been successfully applied to many applications in civil engineering and structural engineering [11]. Jeyasehar et al. [10] designed and carried out an experimental program to induce the desired extents of damages in the prestressed concrete beams and generate the training and test data for a feed forward ANN and demonstrated the feasibility of using an ANN trained with only natural frequency data to assess the damage in prestressed concrete beams. Parthiban et al. [12] analyzed the corrosion of steel in concrete using $\mathrm{NN}$, and they observed that the error encountered was only $5 \%$ for the predictions made from the NN model. Peng et al. [13] used a neural network to analyze the chloride diffusion in concrete and they found that the predictions given by the NN with cascade-correlation algorithm were in good agreement with the test results in both steady and unsteady states. Kewalramani and Gupta [14] conducted a study for prediction of compressive strength of concrete which was done using multiple regression analysis and artificial neural networks. A comparison between two methods depicted that artificial neural networks can be used to predict the compressive strength of concrete effectively. All these above studies indicate that artificial neural networks offer a powerful and reliable tool for solving some problems in civil engineering.

This paper reports a study with an objective of employing ANNs to estimate the carbonation depth in the prestressed concrete beams, and two feed forward neural networks of Back Propagation Neural Network (BPNN) and Radial Basis Function Neural Network (RBFNN) are applied here. The BPNN, trained using the standard error back-propagation algorithm, is widely used in many applications [11]. However, one major limitation of this training algorithm is that the architecture of the network has to be fixed in advance, while the RBFNN, whose nodes in hidden layer are described by radial basis function, can automatically synthesize suitable network architecture with K-Nearest Neighbor algorithm. In general, the BPNN can better construct the global approximations to the input-output mapping, whereas an RBFNN employs the exponentially decaying localized inputoutput mapping which can effectively model the large variation locally [11]. In this study, the two abovementioned ANNs are used to predict the depth of concrete carbonation.
Besides, in order to get the train and test data, an accelerated carbonation experiment of prestressed concrete is carried out. Next, we explain the data generation for the two ANNs from the experimental results and perform the training and testing work using MATLAB. The conclusions of the present study are presented at last, and they prove that the ANN is an effective tool to predict the carbonation depth in concrete.

\section{Experimental Investigation}

2.1. Preparation of Specimens. In order to clarify the influence of stress states of prestressed concrete on carbonation, three series of concrete prisms, Series A, Series B, and Series C, were subjected to rapid carbonation experiment. Series A and Series B were employed to clarify the influence of compressive stress and tensile stress on concrete carbonation depth, respectively. Series C was used as referential specimens with no stress in concrete. All of these test prisms were cast in a laboratory using high-early-strength Portland cement 52.5R, provided by China Jiangnan Cement Co., Ltd, and locally available crushed gravel $(20 \mathrm{~mm}$ maximum size and $1550 \mathrm{~kg} / \mathrm{m}^{3}$ density) and natural sand (fineness modulus of 2.40) as coarse and fine aggregates, respectively. The concrete mix was prepared in accordance with Chinese Standard, JGJ/T55-96 [15]. Both aggregates were pre soaked in water before batching. All batched aggregates were stored in airtight containers to ensure no moisture loss before mixing. At the same time, moisture contents of the aggrebbbgates were determined and adjustments were then made to the mix proportions. The design strength of concrete was specified as $40 \mathrm{MPa}$ which is usually used for actual PC structures. Details of the mix proportions are given in Table 1.

All prestressed concrete prisms, $150 \times 150 \times 400 \mathrm{~mm}$ for Series A and $100 \times 100 \times 400 \mathrm{~mm}$ for Series B and C, were cast in two layers, and each layer was compacted using a vibrating. For each prism of Series A, a circle hole, at the center of cross section, was left with a diameter of $32 \mathrm{~mm}$. All mixing and casting were carried out in a standard laboratory condition at $23 \pm 2{ }^{\circ} \mathrm{C}$ and $50 \pm 5 \% \mathrm{RH}$. After formwork removal at 24 hours, all specimens were covered with wet sacking and plastic sheets for a further 2 days and then were nature-cured indoors up to 28 days of age.

Figures 1 and 2 show the methods to induce different stress in concrete for Series A and Series B, respectively. For Series A, three different compression stress levels were designed and performed by drawing the prestressing wire in the prepared hole, as shown in Figure 1. The tensile strength of the wire, a diameter of $6 \mathrm{~mm}$, is $1570 \mathrm{~N} / \mathrm{mm}^{2}$. while, in order to produce different tension stress states in concrete of Series B, an equivalent setup in which two beams were loaded in a four-point flexure was adopted, and its schematic diagram is shown in Figure 2. Details of stress states for Series $\mathrm{A}$ and $\mathrm{B}$ are given in Table 2 .

In order to analyze the influence of stress state on carbonation depth, an index, stress level $\lambda_{\sigma}$, is defined as the ratio of the real stress value in concrete to the design value of concrete strength, expressed as

$$
\lambda_{\sigma}=\frac{\sigma_{c(t)}}{f_{c(t)}}
$$


TABLE 1: Mix proportion of concrete.

\begin{tabular}{cccccccc}
\hline Grade & W/C & Cement $\left(\mathrm{kg} / \mathrm{m}^{3}\right)$ & Water $\left(\mathrm{kg} / \mathrm{m}^{3}\right)$ & $\begin{array}{c}\text { Fine aggregate } \\
\left(\mathrm{kg} / \mathrm{m}^{3}\right)\end{array}$ & $\begin{array}{c}\text { Coarse aggregate } \\
\left(\mathrm{kg} / \mathrm{m}^{3}\right)\end{array}$ & $\begin{array}{c}\text { Water reducing } \\
\text { admixture }(\%)\end{array}$ & $\begin{array}{c}28-\text {-day } \\
\text { compressive } \\
\text { strength }(\mathrm{MPa})\end{array}$ \\
\hline $\mathrm{C} 40$ & 0.40 & 450 & 180 & 672.6 & 1097.4 & 0.45 & 42.4 \\
\hline
\end{tabular}

Note that W/C is the ratio of water to cement in $1 \mathrm{~m}^{3}$ concrete.

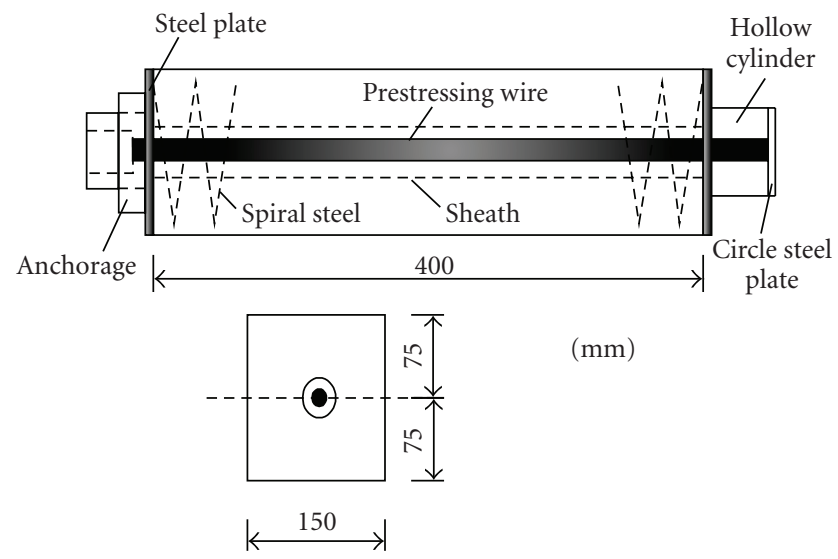

Figure 1: Compressive configuration for Series A beams.

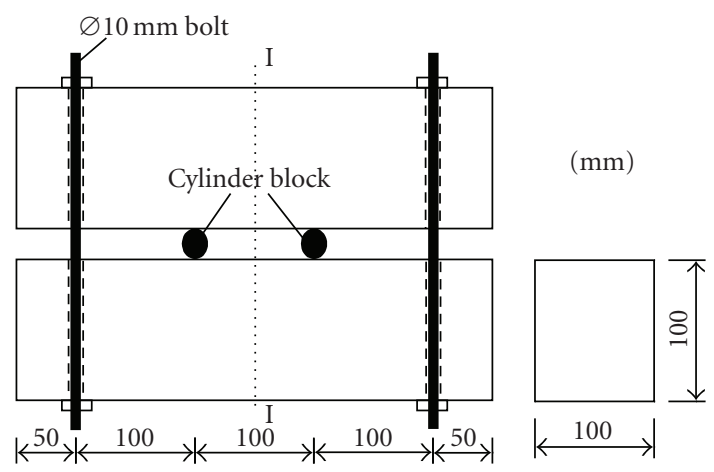

Figure 2: Tensile configuration for Series B beams.

where $f_{c}$ is the designed compressive strength of concrete in Chinese Standard 50010-2002 [16], $f_{c}=0.67 f_{c \text {,cube150 }} / 1.4$, and $f_{c \text {,cube } 150}$ is the $150 \mathrm{~mm}$-cubic compressive strength of concrete; $f_{t}$ is the designed tensile strength of concrete, $f_{t} \approx$ $0.09 \sim 0.10 f_{c} ; \sigma_{c}$ is the applied compressive stress in concrete and marked as a negative value; $\sigma_{t}$ is the applied tensile stress in concrete which is measured at ultimate fiber concrete in middle tensile zones; that is, the measuring position is near the centerline I-I in Figure 2.

2.2. Accelerated Carbonation Test. The natural carbonation process of concrete is rather slow due to the low concentration of carbon dioxide in the environment, which is only about $0.03 \%-0.05 \%$ by volume. The process may last more than ten years in a good quality concrete. In the experimental work, it is desirable to accelerate the process to shorten the duration of testing. Here, an accelerated carbonation test

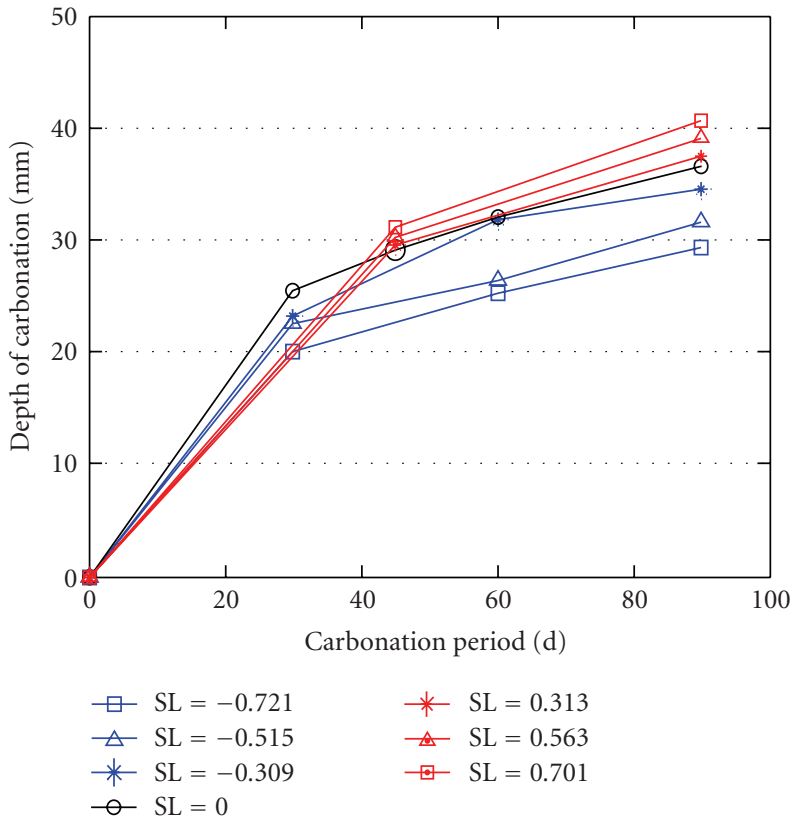

Figure 3: Relationship between carbonation depth and testing time.

was conducted by increasing the concentration of $\mathrm{CO}_{2}$ in the carbonation box, in which the $\mathrm{CO}_{2}$ concentration was $20 \pm 3 \%$ by volume, with $20 \pm 5^{\circ} \mathrm{C}$ and $70 \pm 5 \%$ relative humidity. The accelerated test was performed in accordance with Chinese Standard, GBJ82-85 [17], and the total period of the test was 3 months.

Before testing, five surfaces of all specimens were coated with epoxy resin, and only one tested surface was opened to expose the accelerated carbonation environment. When the samples reach the carbonated age to be tested, a number of $50 \mathrm{~mm}$ long, $50 \mathrm{~mm}$ diameter, small cylinders were cut from the specimens, and then the cylinders' surfaces were sprayed with phenolphthalein indicator. Measurements of the depth of carbonation were performed at 3 points and the averaged depths were obtained finally. Then the specimens were repaired and put into carbonation box again.

\section{Elements of Neural Network}

3.1. Brief Introduction of Artificial Neural Network. The Back Propagation (BP) Neural Network is a multilayer feed-forward network with a back-propagation learning algorithm, which consists of an input layer, one or more hidden layer(s), and an output layer. One major limitation of this training algorithm is that the architecture of the network 
TABLE 2: Stress states and carbonation depths of all specimens.

\begin{tabular}{|c|c|c|c|c|c|c|}
\hline \multirow[b]{2}{*}{ Number } & \multirow[b]{2}{*}{$\mathrm{W} / \mathrm{C}$} & \multicolumn{3}{|c|}{ Stress states in concrete } & \multirow[b]{2}{*}{$\begin{array}{l}\text { Testing age } \\
\text { (days) }\end{array}$} & \multirow[b]{2}{*}{$\begin{array}{l}\text { Carbonation } \\
\text { depth }(\mathrm{mm})\end{array}$} \\
\hline & & $\begin{array}{c}f_{c(t)} \\
(\mathrm{MPa})\end{array}$ & $\begin{array}{c}\text { Applied stress } \\
\sigma_{c(t)}(\mathrm{MPa})\end{array}$ & $\begin{array}{c}\text { Stress level } \\
\lambda_{\sigma} \\
\end{array}$ & & \\
\hline \multicolumn{7}{|c|}{ Specimens of Series A } \\
\hline $\mathrm{A} 1$ & 0.4 & 20.30 & -6.27 & -0.309 & 30 & 23.20 \\
\hline A2 & 0.4 & 20.30 & -6.27 & -0.309 & 60 & 31.90 \\
\hline A3 & 0.4 & 20.30 & -6.27 & -0.309 & 90 & 34.45 \\
\hline A4 & 0.4 & 20.30 & -10.45 & -0.515 & 30 & 22.50 \\
\hline A5 & 0.4 & 20.30 & -10.45 & -0.515 & 60 & 26.38 \\
\hline A6 & 0.4 & 20.30 & -10.45 & -0.515 & 90 & 31.56 \\
\hline A7 & 0.4 & 20.30 & -14.64 & -0.721 & 30 & 19.95 \\
\hline A8 & 0.4 & 20.30 & -14.64 & -0.721 & 60 & 25.13 \\
\hline A9 & 0.4 & 20.30 & -14.64 & -0.721 & 90 & 29.19 \\
\hline \multicolumn{7}{|c|}{ Specimens of Series B } \\
\hline B10 & 0.4 & 1.84 & 0.576 & 0.313 & 45 & 29.60 \\
\hline B11 & 0.4 & 1.84 & 0.576 & 0.313 & 90 & 37.50 \\
\hline B12 & 0.4 & 1.84 & 1.036 & 0.563 & 45 & 30.20 \\
\hline B13 & 0.4 & 1.84 & 1.036 & 0.563 & 90 & 39.10 \\
\hline B14 & 0.4 & 1.84 & 1.290 & 0.701 & 45 & 31.15 \\
\hline B15 & 0.4 & 1.84 & 1.290 & 0.701 & 90 & 40.50 \\
\hline \multicolumn{7}{|c|}{ Specimens of Series C } \\
\hline $\mathrm{C} 16$ & 0.4 & - & 0 & 0 & 30 & 25.45 \\
\hline $\mathrm{C} 17$ & 0.4 & - & 0 & 0 & 45 & 29.10 \\
\hline $\mathrm{C} 18$ & 0.4 & - & 0 & 0 & 60 & 31.92 \\
\hline C19 & 0.4 & - & 0 & 0 & 90 & 36.45 \\
\hline
\end{tabular}

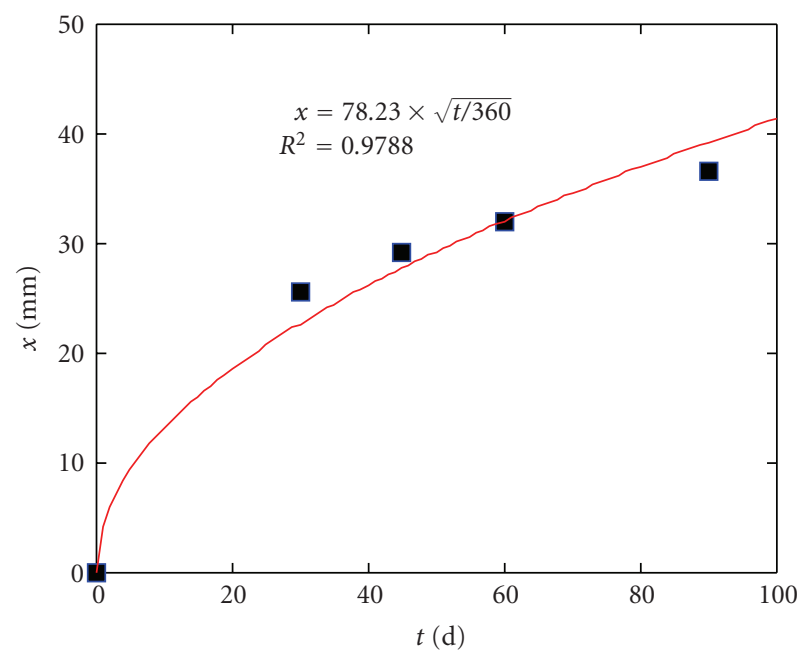

Test results

Fit curve

FIgURE 4: Fit curve for non stress specimen C.

has to be fixed in advance. This means that the end user must design a suitable architecture by a costly trial-and-error approach. If the architecture is too small, the network may not have sufficient degrees of freedom to correctly learn the carbonation depth. On the other hand, if the network is too

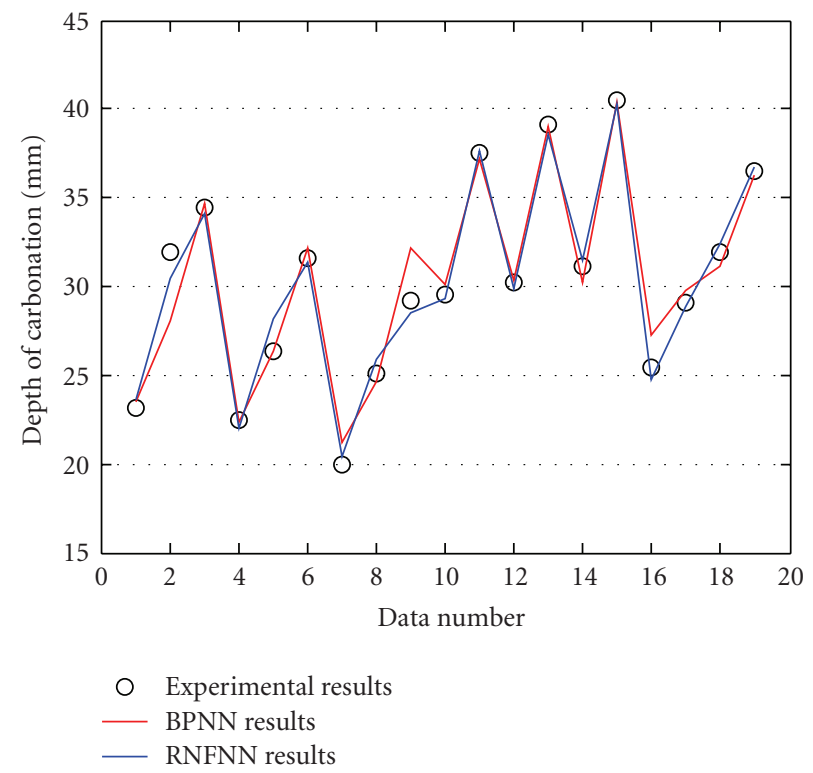

FIGURE 5: Relationship between the two ANNs' training and testing results and the experiment results.

large, then it may not converge during training, or it may overfit the data and memorize the depth history rather than generalize it [13]. Therefore, the key problem encountered by BPNN is to determine the network structure in the number 


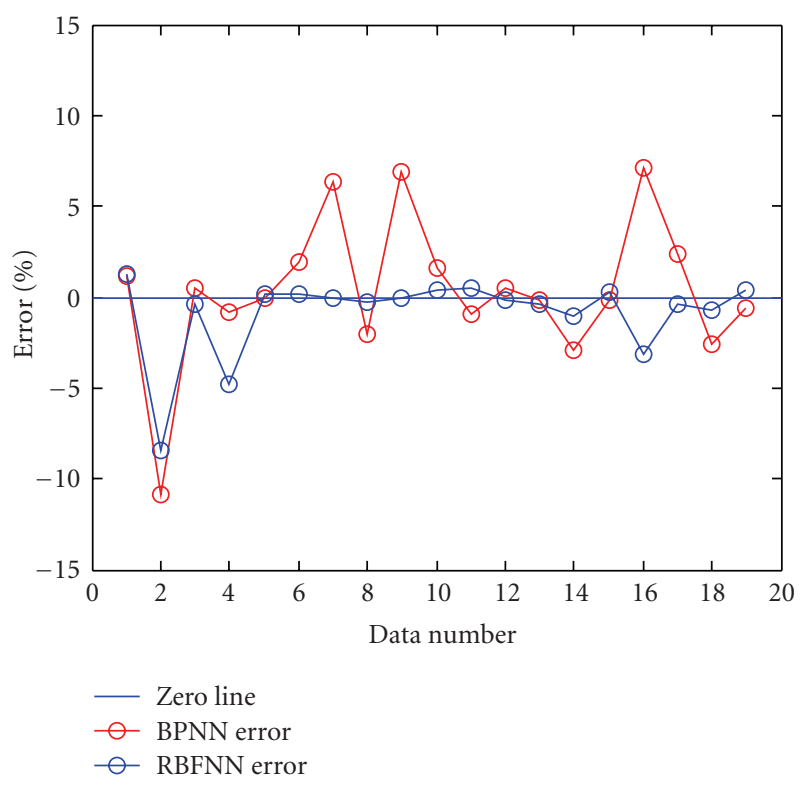

FIGURE 6: Percentage error of the training and testing results of two ANNs.

of hidden layers and the number of hidden neurons in each layer. This means that the end user must design a suitable architecture by a costly trial-and-error approach.

The Radial Basis Function (RBF) neural network is also a kind of feed forward network architecture with only one hidden layer. The RBFNN belongs to the group of kernel function nets that utilize simple kernel functions as the hidden neurons, distributed in different neighborhoods of the input space, and whose responses are essentially local in nature. The RBF produces a significant nonzero response only when the input falls within a small-localized region of the input space $[18,19]$. In RBF nets, learning is generally a two-stage process involving first the recruitment of the necessary number of hidden neurons, to reflect the distribution of training data in the input space. Then the connections between hidden and output layers are adjusted for optimal fit to the data. This is done in a supervised manner. These two operations are automated in the learning algorithm [11]. In MATLAB, learning is started from zero neuron at first. By comparing the output error, the number of neuron is added automatically until the error requirement is matched.

3.2. Application of ANN. The main objective of this study is to predict carbonation depth of prestressed concrete under different stress states. And, an experimental research was performed to obtain practical carbonation results. As seen in Table 2, stress level of concrete (SL) and testing age (TA) had significant influences on carbonation depth of the concretes. Therefore, these two very important parameters are taken into account in the proposed ANN model. Additionally, some very important concrete mixture parameters such as water-cement ratio $(\mathrm{W} / \mathrm{C})$, cement-fine aggregate ratio (C/FA), and cement-coarse aggregate ratio (C/CA) are also defined as the other input parameters of the proposed ANN model. Meanwhile, the depth of carbonation (DC) is selected as the output parameter of the proposed model. In order to eliminate the influence of different parameters' dimension and acquire accurate results, some input and output parameters should be normalized in the range of [0: 1] via (2). In this study, parameters of SL, W/C, C/FA, and $\mathrm{C} / \mathrm{CA}$ are all in the range of -1 to 1 , while the TA and DC parameters are beyond this range greatly and should be normalized. All input and output parameters are given in Table 3:

$$
\alpha_{i}=\frac{x_{i}-x_{\min }}{x_{\max }-x_{\min }}
$$

where $\alpha_{i}$ represents parameters used in the ANN training process; $x_{i}$ is the $i$ th value of input/output parameter $x_{\max }, x_{\min }$ the maximum and minimum values of the $i$ th parameter, respectively.

To BPNN model, a three-layer neuron network is chosen and it is essential to determine the number of hidden layer neuron rationally. After trial and error, a 5-10-1 neuron network is adopted to develop the BPNN model. That means that there are 5 nodes in the input layer, corresponding to 5 factors of SL, TA, W/C, C/FA and C/CA, one hidden layer with 10 nodes, and one node in the output layer corresponding to DC, while, in the RBFNN, the input and output parameters are the same with BPNN and the node number of hidden layer need not be confirmed. All the training and testing work are done by using MATLAB.

\section{Results and Discussion}

4.1. Experimental Results and Discussion. The results of accelerated carbonation experiment are also listed in Table 2. Figure 3 distinctly shows the relationship between carbonation depths and carbonation periods for concretes with different stress levels. The depths of carbonation were observed after the period of 30, 45, 60, and 90 days.

As generally known, the carbonation depth in a given concrete progresses with exposure duration. However, the rate of carbonation, in the cases of accelerated carbonation conditions and natural exposure conditions, reduces with respect to time period and is usually considered as proportional to the square root of exposure period [5-7]. According to square root theory, the depth of carbonation, $x$, can be considered related to the exposure duration, $t(a)$, in accordance with Fick's first law of diffusion [5-7], expressed as

$$
x=k \sqrt{t} .
$$

Here, $k$ is the accelerated carbonation coefficient $(\mathrm{mm}$ $/ \sqrt{a}$ ), usually considering these factors including environmental conditions, material property and concentration of $\mathrm{CO}_{2}$, and so forth. But, the stress level of concrete is scarcely taken into account.

From Figure 3, however, it can be concluded that the stress level in concrete has significant influence on concrete carbonation process and its depth. Under the same 
conditions, the carbonation rate in tensile concrete is faster than that in none stress concrete, while the carbonation rate in compressive concrete is slower than that in none stress concrete. For example, at the total time period of 90 days, the depth of carbonation in the tensile specimen $\left(\lambda_{\sigma}=0.701\right)$ is 1.39 times higher than that of compressive specimen $\left(\lambda_{\sigma}=-0.721\right)$. The possible reason for this would be that tensile stress in concrete will damage the aggregatepaste interface and increase the connectivity of pores and the permeability of concrete, so that the diffusion speed of $\mathrm{CO}_{2}$ and carbonation rate will be expedited [20] and that the compressive stresses in concrete impede $\mathrm{CO}_{2}$ diffusion, which can be attributed to the reduction in the porosity of the concrete because the compressive stresses may partially close some microcracks in concrete.

So, to prestressed concrete structures, the stress level of concrete should be considered when the depth of carbonation is calculated. Based on (3), the depth of carbonation considering the stress level of concrete could be described as

$$
x=K \sqrt{t}=k \cdot k_{\sigma} \cdot \sqrt{t},
$$

where $k_{\sigma}$ is an influenced coefficient of stress level of concrete; $K$ represented the integrated coefficient of carbonation, which also takes the stress level into account ( $\mathrm{mm}$ $/ \sqrt{a})$.

The coefficient $k$ can be obtained from the accelerated experiment results of none stress specimen, and the average value of $k$ got from our experiment is $78.23 \mathrm{~mm} / \sqrt{a}$ (see Figure 4). But, it should be noticed that the carbon dioxide concentration $\left(c_{0}\right)$ contained in the conventional environment is normally about $0.03 \%$, whereas the concentration of $20 \%$ was performed in the accelerated test. Hence, the ratio of carbonation coefficient of the two cases could be expressed in terms of carbon dioxide concentration as shown in (5) [21]. It meant that the carbonation rate under environmental conditions is approximately 25.82 times slower than that of the accelerated carbonation test carried out in this study:

$$
\frac{k_{\mathrm{acc}}}{k_{\mathrm{env}}}=\frac{\sqrt{c_{0, \mathrm{acc}}}}{\sqrt{c_{o, \mathrm{env}}}} \approx \frac{\sqrt{20 \%}}{\sqrt{0.03 \%}}=25.82 .
$$

The coefficient $k_{\sigma}$ could be assumed as a polynomial relation with the stress level as shown in (6):

$$
k_{\sigma}=1+\alpha\left(\frac{\sigma_{c(t)}}{f_{c(t)}}\right)+\beta\left(\frac{\sigma_{c(t)}}{f_{c(t)}}\right)^{2}=1+\alpha \cdot \lambda_{\sigma}+\beta \cdot \lambda_{\sigma}^{2} .
$$

Here, $\alpha$ and $\beta$ are two recursive coefficients. Based on the results of our accelerated carbonation test, two parameters of $\alpha$ and $\beta$ are obtained. And the depths of carbonation, $x(\mathrm{~mm})$, related to the exposure time, $t(\mathrm{~d})$, in this study can be expressed as follows:

$$
\begin{aligned}
& \text { Compression : } x= 78.23 \times\left(1+0.0604 \lambda_{\sigma}-0.3843 \lambda_{\sigma}^{2}\right) \\
& \cdot \sqrt{t / 360}, \\
& \text { Tension : } x= 78.23 \times\left(1+0.0518 \lambda_{\sigma}+0.1153 \lambda_{\sigma}^{2}\right) \\
& \cdot \sqrt{t / 360} .
\end{aligned}
$$

4.2. ANN Training and Testing Results and Discussion. The training and testing results based on proposed BPNN and RBFNN models are listed in Table 3. Figure 5 distinctly shows the relationships between the prediction results of two above ANNs and the experimental results of our accelerated carbonation test. The percentage errors of training and testing results are given in Figure 6.

From Figures 5 and 6 , it can be obtained that the predictions of two proposed ANNs are perfect, and that the maximum absolute percentage errors of BPNN and RBFNN are $10.88 \%$ and $8.46 \%$ for both training and testing data sets, respectively. Therefore, the two ANNs appear to have a high generalization capability in the prediction of carbonation depth in prestressed concrete, and it is concluded that artificial neural network (ANN) technology is a feasible way to analyze and predict carbonation depth in concrete.

Besides, based on the prediction results of two ANNs, the RBFNN model shows a better prediction precision in comparison to the proposed 5-10-1 BPNN model. It is known that the precision of BPNN model may be pertinent to the network architecture, mainly the number of hidden layer. That is, the prediction precision of our given BPNN maybe can be improved by adding the number of hidden layers appropriately, which may be higher than that of RBFNN. This issue is just about one major limitation of BP neural network mentioned in the initial discussion. Therefore, based on two aspects including prediction precision and application convenience, it is commendatory to choose RBFNN to predict the carbonation depth of concrete and solve other problems in civil engineering.

\section{Conclusion}

In this study, two artificial neural network (ANN) models, BPNN and RBFNN, are built to predict the depth of carbonation of prestressed concrete based on our accelerated carbonation test. The following conclusions are drawn from this study.

(i) Accelerated carbonation test results indicate that stress level of prestressed concrete has a significant influence on concrete carbonation process. Tension stress in concrete will damage the aggregate-paste interface, increase the connectivity of pores, and finally improve the carbonation rate. In contrast, compression stress in concrete will reduce the porosity of the concrete, increase the compactness of concrete, and finally slow the carbonation process. And this influence could be expressed by the stress level, $\sigma_{c} / f_{c}$ or $\sigma_{t} / f_{t}$, of concrete.

(ii) It is found that the two ANN models, BPNN and RBFNN, seem to have a high prediction and generalization capability in the prediction of carbonation depth of prestressed concretes in terms of stress level of concrete, water-cement ratio, cement-fine aggregate ratio, cement-coarse aggregate ratio, and testing age. For both training and testing data sets, the maximum absolute percentage errors of BPNN and RBFNN are $10.88 \%$ and $8.46 \%$, respectively. On 
TABLE 3: Normalized input/output pairs and the training and testing results.

\begin{tabular}{|c|c|c|c|c|c|c|c|c|}
\hline \multirow{2}{*}{ Number } & \multicolumn{5}{|c|}{ Input } & \multicolumn{3}{|c|}{ Output/DC(mm) } \\
\hline & SL & TA & $\mathrm{W} / \mathrm{C}$ & $\mathrm{C} / \mathrm{FA}$ & $\mathrm{C} / \mathrm{CA}$ & Experiment & BPNN & RBFNN \\
\hline \multicolumn{9}{|l|}{ Training } \\
\hline $\mathrm{A} 1$ & -0.309 & 0 & 0.4 & 0.669 & 0.410 & 23.20 & 23.47 & 23.57 \\
\hline $\mathrm{A} 3$ & -0.309 & 1.0 & 0.4 & 0.669 & 0.410 & 34.45 & 34.62 & 34.10 \\
\hline A5 & -0.515 & 0.5 & 0.4 & 0.669 & 0.410 & 26.38 & 26.38 & 28.23 \\
\hline A6 & -0.515 & 1.0 & 0.4 & 0.669 & 0.410 & 31.56 & 32.17 & 31.37 \\
\hline A7 & -0.721 & 0 & 0.4 & 0.669 & 0.410 & 19.95 & 21.22 & 20.38 \\
\hline A8 & -0.721 & 0.5 & 0.4 & 0.669 & 0.410 & 25.13 & 24.62 & 25.84 \\
\hline $\mathrm{B} 10$ & 0.313 & 0.25 & 0.4 & 0.669 & 0.410 & 29.60 & 30.07 & 29.28 \\
\hline $\mathrm{B} 12$ & 0.563 & 0.25 & 0.4 & 0.669 & 0.410 & 30.20 & 30.35 & 29.92 \\
\hline B13 & 0.563 & 1.0 & 0.4 & 0.669 & 0.410 & 39.10 & 39.03 & 38.54 \\
\hline B15 & 0.701 & 1.0 & 0.4 & 0.669 & 0.410 & 40.50 & 40.43 & 40.22 \\
\hline $\mathrm{C} 17$ & 0 & 0.25 & 0.4 & 0.669 & 0.410 & 29.10 & 29.80 & 28.87 \\
\hline C19 & 0 & 1.0 & 0.4 & 0.669 & 0.410 & 36.45 & 36.23 & 36.69 \\
\hline \multicolumn{9}{|l|}{ Testing } \\
\hline $\mathrm{A} 2$ & -0.309 & 0.5 & 0.4 & 0.669 & 0.410 & 31.90 & 28.43 & 30.47 \\
\hline A4 & -0.515 & 0 & 0.4 & 0.669 & 0.410 & 22.50 & 22.31 & 22.06 \\
\hline A9 & -0.721 & 1.0 & 0.4 & 0.669 & 0.410 & 29.19 & 31.21 & 28.50 \\
\hline B11 & 0.313 & 1.0 & 0.4 & 0.669 & 0.410 & 37.50 & 37.15 & 37.69 \\
\hline B14 & 0.701 & 0.25 & 0.4 & 0.669 & 0.410 & 31.15 & 30.24 & 31.48 \\
\hline $\mathrm{C} 16$ & 0 & 0 & 0.4 & 0.669 & 0.410 & 25.45 & 27.26 & 24.73 \\
\hline $\mathrm{C} 18$ & 0 & 0.5 & 0.4 & 0.669 & 0.410 & 31.92 & 31.10 & 32.43 \\
\hline
\end{tabular}

account of the complexity of carbonation process, these errors are acceptable in civil engineering. Therefore, ANN is an effective tool to predict the carbonation depth in concrete.

(iii) The precision of BPNN model may be pertinent to the network architecture, and the end user must design a suitable architecture by a costly trial-anderror approach, while the node number of hidden layer in RBFNN is adjusted automatically in the learning algorithm. Based on prediction accuracy and convenience of application, it is commendatory to choose RBFNN to predict the carbonation depth of concrete and solve other problems in civil engineering.

(iv) Using ANN to solve any problem, it is very significant to obtain enough training and testing data to build a perfect neural network. In our study, some specimens with $\mathrm{W} / \mathrm{C}=0.5$ were abandoned because they were carbonated completely in the accelerated experiment. Therefore, further study will be performed to gain more carbonation data and formulate a better procedure to predict carbonation depth in prestressed concrete beams using ANNs. The optimized program developed by using ANN technology can provide a new practical approach to analysis the issue of concrete carbonation.

\section{Acknowledgments}

The authors would like to express their thanks to Professor Zhi-tao LV, college of civil engineering, Southeast University,
China, for helping finishing the experiment research. The financial supports of the National Natural Science Foundation of China via Grant nos. 50478089 and 50908103 are greatly acknowledged.

\section{References}

[1] W. Podolny, "Corrosion of prestressing steels and its mitigation," Journal of the Precast/Prestressed Concrete Institute, vol. 37, no. 5, pp. 34-54, 1992.

[2] T. Adrian and P. E. Ciolko, "Corrosion and prestressed concrete bridges," in Proceedings of the Structures Congress of the Forensic Engineering Symposium, New York, NY, USA, April 2005.

[3] C.-F. Chang and J.-W. Chen, "The experimental investigation of concrete carbonation depth," Cement and Concrete Research, vol. 36, no. 9, pp. 1760-1767, 2006.

[4] K. Sisomphon and L. Franke, "Carbonation rates of concretes containing high volume of pozzolanic materials," Cement and Concrete Research, vol. 37, no. 12, pp. 1647-1653, 2007.

[5] V. G. Papadakis, "Effect of supplementary cementing materials on concrete resistance against carbonation and chloride ingress," Cement and Concrete Research, vol. 30, no. 2, pp. 291299, 2000.

[6] CEB Bulletin 238, "New Approach to Durability DesignAn Example for carbonation induced corrosion," Lausanne, Switzerland, 1997.

[7] Y. F. Houst and F. H. Wittmann, "Depth profiles of carbonates formed during natural carbonation," Cement and Concrete Research, vol. 32, no. 12, pp. 1923-1930, 2002.

[8] A. Steffens, D. Dinkler, and H. Ahrens, "Modeling carbonation for corrosion risk prediction of concrete structures," Cement and Concrete Research, vol. 32, no. 6, pp. 935-941, 2002. 
[9] A. V. Saetta and R. V. Vitaliani, "Experimental investigation and numerical modeling of carbonation process in reinforced concrete structures_-part I: theoretical formulation," Cement and Concrete Research, vol. 34, no. 4, pp. 571-579, 2004.

[10] C. A. Jeyasehar and K. Sumangala, "Damage assessment of prestressed concrete beams using artificial neural network (ANN) approach," Computers and Structures, vol. 84, no. 2627, pp. 1709-1718, 2006.

[11] M. Y. Rafiq, G. Bugmann, and D. J. Easterbrook, "Neural network design for engineering applications," Computers and Structures, vol. 79, no. 17, pp. 1541-1552, 2001.

[12] T. Parthiban, R. Ravi, G. T. Parthiban, S. Srinivasan, K. R. Ramakrishnan, and M. Raghavan, "Neural network analysis for corrosion of steel in concrete," Corrosion Science, vol. 47, no. 7, pp. 1625-1642, 2005.

[13] J. Peng, Z. Li, and B. Ma, "Neural network analysis of chloride diffusion in concrete," Journal of Materials in Civil Engineering, vol. 14, no. 4, pp. 327-333, 2002.

[14] M. A. Kewalramani and R. Gupta, "Concrete compressive strength prediction using ultrasonic pulse velocity through artificial neural networks," Automation in Construction, vol. 15, no. 3, pp. 374-379, 2006.

[15] JGJ/T55-96, "Technical standard of mix design for ordinary concrete," Chinese Standard, 1996.

[16] GB50010-2002, "Code for design of concrete structures," Chinese Standard, 2002.

[17] GBJ82-85, "Test methods of long tern performance and durable performance for ordinary concrete," Chinese Standard, 1985.

[18] N. Jiang, Z. Zhao, and L. Ren, "Design of structural modular neural networks with genetic algorithm," Advances in Engineering Software, vol. 34, no. 1, pp. 17-24, 2003.

[19] S. Rajasekaran and R. Amalraj, "Predictions of design parameters in civil engineering problems using SLNN with a single hidden RBF neuron," Computers and Structures, vol. 80, no. 31, pp. 2495-2505, 2002.

[20] R. Francois and J. C. Maso, "Effect of damage in reinforced concrete on carbonation or chloride penetration," Cement and Concrete Research, vol. 18, no. 6, pp. 961-970, 1988.

[21] K. Sisomphon and L. Franke, "Carbonation rates of concretes containing high volume of pozzolanic materials," Cement and Concrete Research, vol. 37, no. 12, pp. 1647-1653, 2007. 

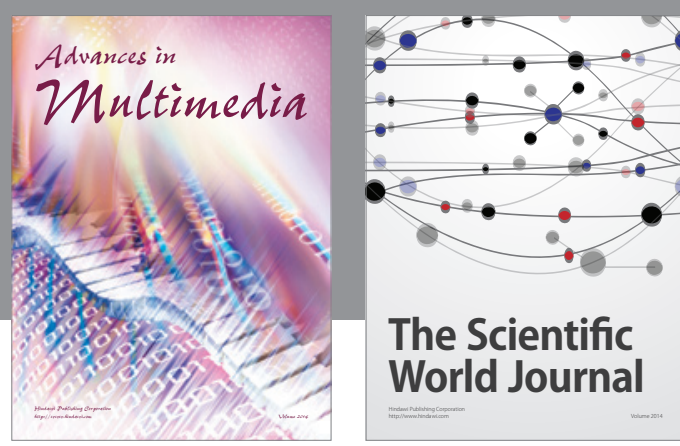

The Scientific World Journal
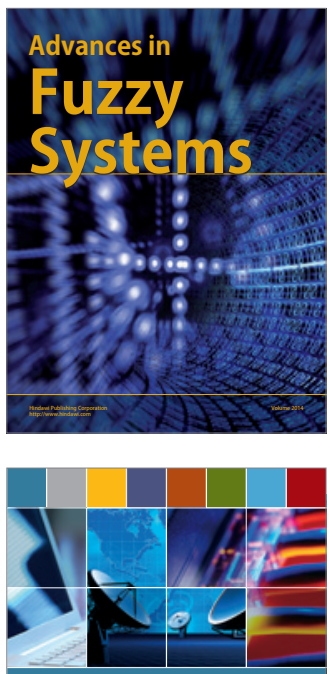

Computer Networks and Communications
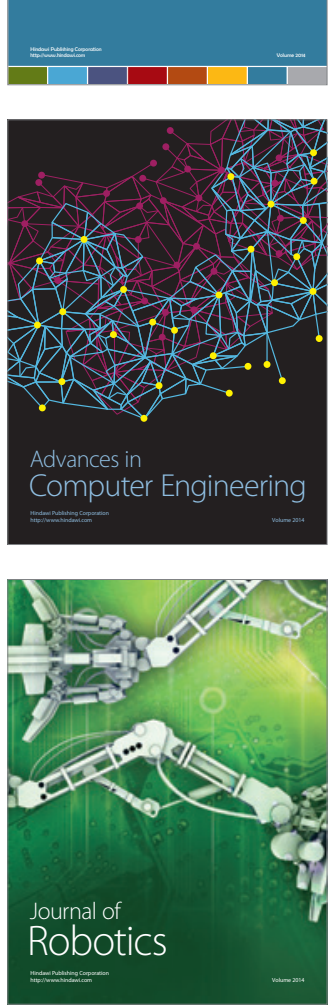
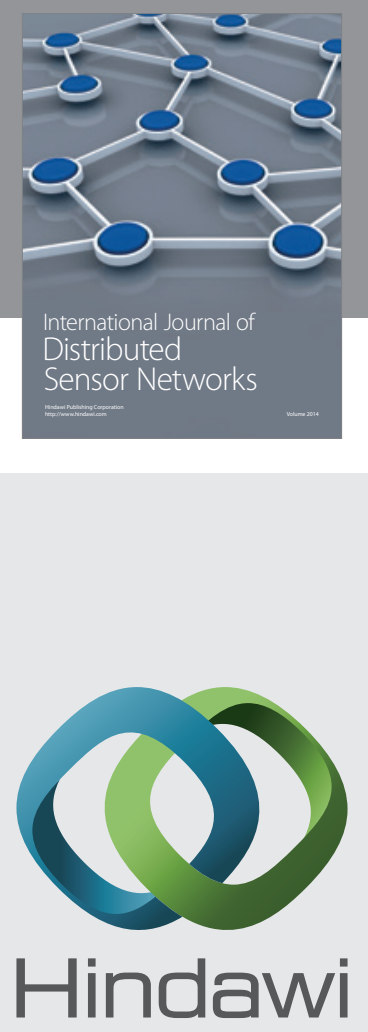

Submit your manuscripts at

http://www.hindawi.com
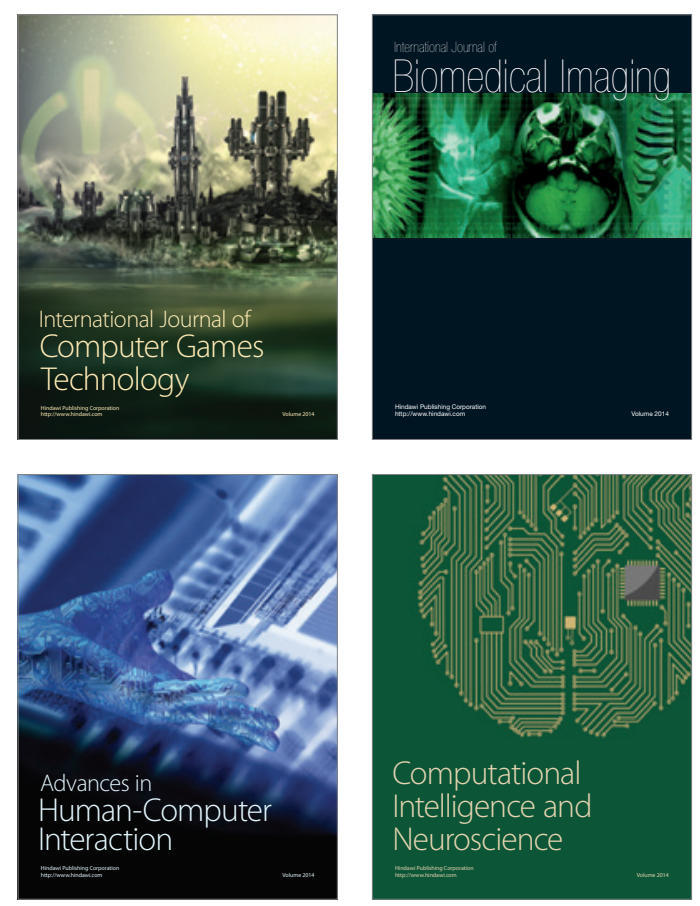
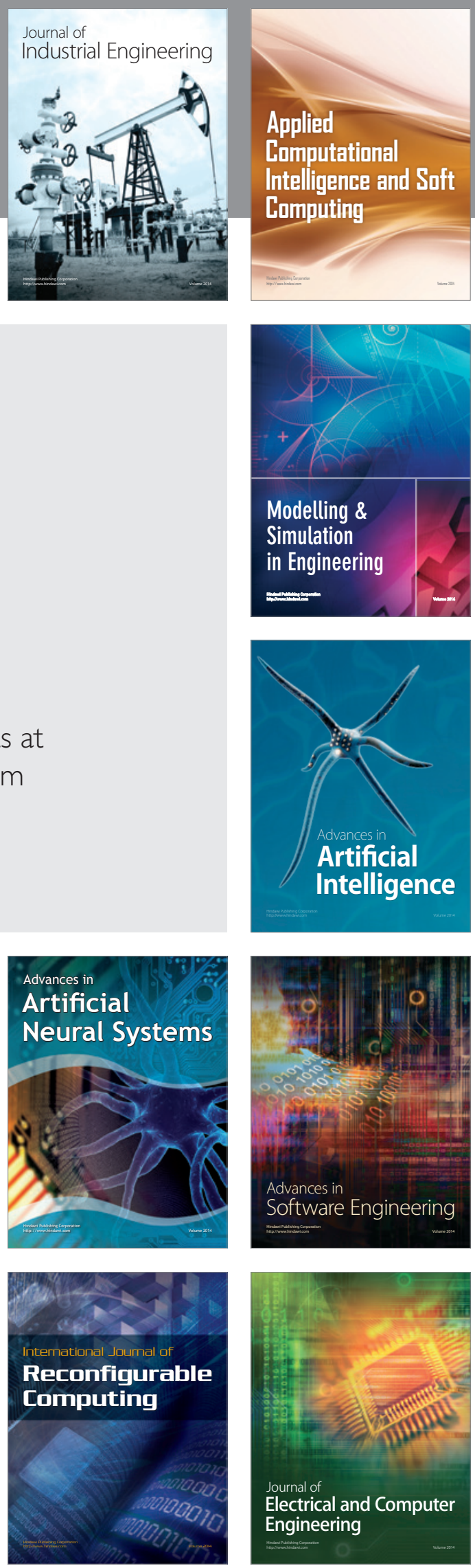